\title{
The management of malignant pleural effusion
}

\author{
M. L. SUtTON \\ M.A., M.R.C.P., F.F.R. \\ Department of Radiotherapy, Hammersmith Hospital, Du Cane Road, London, W.12
}

\begin{abstract}
Summary
Several effective methods exist for the control of malignant pleural effusion: the most effective is iodized talc poudrage, but the relatively short survival times associated with malignant effusions from bronchogenic carcinomas make less elaborate methods more appropriate. $70-80 \%$ of malignant effusions can be controlled by intrapleural instillation of Mustine or the antimalarial drug quinactine. Preliminary removal of as much fluid as possible is an important contributory factor to success. Radioactive colloidal gold is obsolete in pleural effusions.
\end{abstract}

\section{Introduction}

In health there is a massive daily exchange of fluid across the serosal surfaces, and therefore small deviations from normal in the rates of either transudation or absorption can rapidly result in the accumulation of fluid. In malignant effusions, decreased absorption from blockage of subpleural lymphatics and venules is almost certainly more important than increased exudation from the malignant surfaces, and this view is supported by the excellent results achieved by methods of management which do not involve a direct attack on the malignant cell. These methods depend on agents that produce a sterile adhesive serositis, which causes obliteration of the pleural space. The successful obliteration of the space requires that two conditions be satisfied, namely that there be good re-expansion of the underlying lung, and that there be almost complete removal of the fluid before the active agent is introduced into the pleural cavity. If the latter condition is not fulfilled, a portion of the parietal and visceral pleural surfaces will not be in apposition when the induced serositis is at its peak, and this makes pleurodesis less likely. Before the introduction of the active agent, patients with large effusions will usually require continuous tube drainage for 24-48 hours, to avoid the hazardous and unpleasant consequences of rapid removal of large volumes of fluid.

\section{The active agents}

1. Talc. In this country the best results have been obtained from poudrage with iodized talc. The iodine adds its own inflammatory component to that of the talc, and may aid sterility. Jones (1969) found that it controlled $90 \%$ of malignant effusions for the patients' remaining lifetime. Failures with this method are usually due to bronchogenic carcinomas which are blocking a main bronchus and thereby preventing re-expansion of the underlying lung. The blowing of $5 \mathrm{~g}$ of talc powder into the pleural cavity is a painful event, and it requires a general anaesthetic and post-operative opiates, and a wide-bore chest tube may be needed for some days after the procedure.

Talc pleurodesis would seem most indicated in malignant effusions where the underlying neoplastic disease is compatible with appreciable survival, breast cancer for example. Many physicians may feel that it is a rather demanding procedure for patients with lung cancer, in whom the aim is to relieve dyspnoea and cough, and to obviate the need for further aspirations for the duration of a relatively short life. Somewhat less effective, but less elaborate methods are therefore popular.

2. Antimalarials. Some antimalarial drugs, e.g. quinacrine, possess mild antineoplastic properties (Vassey, Edmonds, Irvine et al., 1955), but their effectiveness in controlling effusions resides more in their ability to induce serositis when introduced into the pleural cavity. They have the advantage of being suitable for use when the marrow is functioning poorly from either malignant disease or its treatment, but a minor disadvantage is that daily instillation is required until clinically evident pleuritis occurs. This usually takes $2-3$ days using $600-800$ $\mathrm{mg}$ daily of quinacrine hydrochloride. Dollinger \& Karnofsky (1967) report $70 \%$ control, with few untoward effects apart from the inevitable pleural pain and fever. Very rarely, hallucinations and convulsions occur (Borda \& Krant, 1967).

3. Alkylating agents. Mustine (mechlorethamine) seems to have lost favour as an agent for the control of pleural effusions, although its success rate can equal that of quinacrine. The eclipse of Mustine may be due to past disappointments resulting from its improper use: Mustine is a highly reactive compound in solution, and has a half-life in water of the order of minutes only. Commonly, one suspects, the Mustine is dissolved and left ready on the trolley 
whilst a leisurely (and almost certainly incomplete) chest aspiration is performed, and the relatively spent solution of Mustine and its produces are then instilled through the aspiration set. Under these circumstances satisfactory results will not be obtained. Published reports give an average of 50-60\% of patients adequately controlled with Mustine, for example, Levison (1961). Personal experience suggests that $20 \mathrm{mg}$ of freshly prepared Mustine introduced into a nearly empty pleural space in $200 \mathrm{ml}$ normal saline controls $70 \%$ of effusions. Haematological disturbance is usually not marked, but systemic symptoms may be prominent for up to 48 hours. The very high figure of $87 \%$ with in-life control was reported by Kinsey, Carter \& Klassen (1964), who used $30 \mathrm{mg}$ of Mustine in $150 \mathrm{ml}$ normal saline which was withdrawn after 4 hours, presumably in the hope of minimizing the systemic disturbance. In this series the lung cancer patients had an average survival time of 4.8 months. The local it ritative effect of Mustine is probably at least as important as its antineoplastic effect; this may explain why Thio-Tepa, which produces little serositis, is less effective than Mustine. A further disadvantage of Thio-Tepa is that repeated administration is necessary.

Regrettably, cases are still referred for treatment after the (predictable) failure of intrapleural cyclophosphamide to control an effusion. Cyclophosphamide is activated in the liver, and is unsuitable for regional use.

4. $\beta$-Emitting radio-isotopes. Radioactive colloidal gold is obsolete in the management of pleural effusions, although it is still sometimes useful for ascites, especially when the ascites is caused by ovarian carcinomatosis peritonei. MacKay (1957) reported benefit in only $50 \%$ of cases, and noted that although there was a marked and consistent fall in the concentration of malignant cells in the fluid after radiogold, there was often no effect on the rate of formation of fluid. This is consistent with the hypothesis that subpleural lymphatic blockage is the major cause of fluid accumulation, since the finite range of the $\beta$-particle is less than the depth of many of the lymphatics. The $10 \% \gamma$-ray component of radiogold can have little therapeutic effect, but causes avoidable radiation exposure, which may reach $50 \mathrm{mr}$ per hour at the foot of the patient's bed. Radioactive Yttrium is a pure $\beta$-emitter, and Walter (1960) reported benefit from its use in colloidal form, but it has not become popular. Radio-isotopes are an expensive and relatively ineffective way of irritating the pleura.

It must be conceded that many patients can be satisfactorily managed by repeated simple aspiration, but this approach can be troublesome when it fails, since loculation and encystment are not uncommonly the results, and they make subsequent treatment difficult.

In conclusion, the author's personal preference for the control of malignant effusion in lung cancer is Mustine, because it is effective, expeditious, and cheap. For effusions associated with other primary neoplasms, other approaches are often more appropriate.

\section{References}

Borda, I. \& Krant, M, (1967) Convulsions following intrapleural administration of qunacrine $\mathrm{HCl}$. Journal of the American Medical Association, 201, 1049.

Dollinger, M.R., KrakofF, I.H. \& KarnofsKy, D.A. (1967) Quinacrine in the treatment of neoplastic effusions. Annals of Internal Medicine, 66, 249.

JoNES, E.R. (1969) Treatment of recurrent malignant effusion by iodised talc pleurodesis. Thorax, 24, 69.

Kinsey, D.L., Carter, D. \& Klassen, K.R. (1964) Simplified management of malignant pleural effusion. Archives of Surgery, 89, 389.

LEvison, V.B. (1961) Nitrogen mustard in the palliation of malignant effusions. British Medical Journal, 1, 1143.

MACKAY, N. (1957) Radioactive colloidal gold in the treatment of pleural and peritoneal effusions of malignant origin. Lancet, ii, 761.

VASSEY, J.W., Edmonds, J., Irvin, J.L., Green, J.L. \& Irvin, E.M. (1955) Studies on the administration of quinacrine to tumour bearing mice. Cancer Research, 15, 573.

WALTER, J. (1960) Malignant pleural effusion treated by colloidal radioactive yttrium silicate. British Medical Journal, 2, 1282.

\section{Discussion}

Chairman: DR J. R. MikHAIL

(Central Middlesex Hospital)

DR Mikhail (Central Middlesex Hospital): You were talking about putting nitrogen mustard into pleural effusions. Do you advocate that the fluid is drained completely off just before you install the nitrogen mustard? It has been our practice always to leave some fluid there, then tipping the patient every $10 \mathrm{~min}$ to get complete coverage of the pleuva. It is a very painful procedure to put nitrogen mustard into a dry pleura and because of this I have always left a certain amount of fluid. I wondered what are your views on this.

DR SUTTON (Hammersmith): I quite agree it is difficult to get adequate coverage of the pleura and so what $I$ 